\title{
Radial first or patient first: a case series and meta- analysis of transradial versus transfemoral access for acute ischemic stroke intervention
}

\author{
Adnan H Siddiqui (D) , $1,2,3,4,5$ Muhammad Waqas (D) , 1,3 Jenna Neumaier, ${ }^{6}$ \\ Jeff F Zhang, ${ }^{6}$ Rimal H Dossani, ${ }^{1,3}$ Justin M Cappuzzo, ${ }^{1,3}$ Russell J Van Coevering III, ${ }^{7}$ \\ Hamid H Rai (D) ,', Andre Monteiro, ${ }^{1,3}$ Ashish Sonig, ${ }^{1,3}$ Jason M Davies (1) , 1,3,4,5,8 \\ Kenneth V Snyder, ${ }^{1,3,4,5}$ Elad I Levy (1) 1,2,3,4,5
}

For numbered affiliations see end of article.

\section{Correspondence to} Dr Elad I Levy, University at Buffalo Neurosurgery, 100 High Street, Suite B4, Buffalo, New York 14203, USA; ELevy@ubns. com

Received 18 December 2020 Revised 24 January 2021 Accepted 29 January 2021 Published Online First 25 February 2021

\section{SLinked}

- http://dx.doi.org/10.1136/ neurintsurg-2021-017655

\section{Check for updates}

(c) Author(s) (or their employer(s)) 2021. No commercial re-use. See rights and permissions. Published by BMJ.

To cite: Siddiqui $\mathrm{AH}$,

Waqas M, Neumaier J, et al. $J$ Neurolntervent Surg

2021:13:687-692.

\section{ABSTRACT}

Background Few studies have compared technical success and effectiveness of transradial access (TRA) versus transfemoral access (TFA) for mechanical thrombectomy (MT) for acute ischemic stroke (AIS). We compared the two approaches for technical success, effectiveness, and outcomes.

Methods We retrospectively compared TRA with TFA for AIS MT at our institute. We additionally performed a systematic review and meta-analysis of studies describing the use of TRA alone or in comparison with TFA for MT. Primary outcomes included rate of successful reperfusion (thrombolysis in cerebral infarction (TICI) $\geq 2 b$ ), number of passes, access-site complications, and 3- month mortality and favorable functional outcomes (modified Rankin Scale (mRS) score 0-2).

Results A total of 222 consecutive patients (TRA=93, $T F A=129)$ were included in our case series. The rate of successful reperfusion was significantly higher for the TFA cohort $(91.4 \%$ vs $79.6 \%, P=0.01)$ with lower mean number of passes (1.8 \pm 1.2 vs $2.4 \pm 1.6, \mathrm{P}=0.014)$. Three-month mortality in the TFA group was lower (22.1\% vs $40.9 \%$ for the TRA cohort $(P=0.004)$, with a higher rate of favorable functional outcomes $(51.3 \%$ vs $34.1 \%, P=0.015)$. A meta-analysis of 10 studies showed significant heterogeneity in rates of successful reperfusion $(57.1 \%$ to $95.6 \%$, heterogeneity $=67.55 \%$, $\mathrm{P}=0.001)$. None of the previous comparative studies reported 3-month mortality and functional outcomes. Conclusions This case series demonstrate a higher successful reperfusion rate, fewer passes, lower 3-month mortality, and improved 3-month functional outcomes with TFA. The systematic review highlights the inadequacy of existing evidence. Prospective comparative studies are needed before a 'radial-first' approach can be adopted for stroke intervention.

\section{BACKGROUND}

The premise of the 'radial-first' paradigm for neuroendovascular procedures is the superior safety profile of transradial access (TRA). ${ }^{1-4}$ In addition to a lower rate of access-site complications, TRA allows early ambulation, greater patient comfort, and potentially reduced cost and hospital stay. ${ }^{1-35}$ Several articles have shown the feasibility of the radial-first approach for various indications, including flow diversion, aneurysm coiling, carotid stenting, middle meningeal artery embolization, and acute ischemic stroke. ${ }^{4-11}$

Most studies that describe a radial-first experience are noncomparative case series with considerable selection bias. Few studies provide a direct comparison of TRA with transfemoral access (TFA). ${ }^{8} 12$ Such comparisons are more critical for the endovascular management of acute ischemic stroke than for any other indication. Stroke intervention must be performed emergently and effectively to achieve optimal results. Considerable differences exist between TFA and TRA in terms of technique and device selection. Major limitations of the use of TRA in the context of mechanical thrombectomy (MT) for stroke include limited sheath size, which restricts use of the largest aspiration catheters as well as usage of balloon-guide catheters (BGC). These technical factors are likely to affect the performance of MT.

Previous studies have claimed little difference in the angiographic and clinical outcomes of TRA and TFA for MT. ${ }^{8}{ }^{13-15}$ With the exception of the study conducted by Philips et al, ${ }^{15}$ previous studies on radial stroke intervention are small in size, do not have a direct comparison with a transfemoral cohort, and, more importantly, do not report 3-month mortality and outcomes because they focus on feasibility and safety. Moreover, little consideration was given to technical details and their influence on the associated angiographic outcomes. We have previously presented our initial experience with TRA, which showed the feasibility of TRA for MT; however, due to a small sample size, statistical significance could not be found between the TRA and TFA groups. ${ }^{8}$

A comparison of MT performed via TRA and TFA is essential to justify a radial-first approach. Any evidence of inferiority or a lack thereof should discourage universal use of a radial-first approach for stroke intervention. In this study we aimed to compare the angiographic and clinical outcomes of MT performed with TRA or TFA at our institute. Additionally, we performed a systematic review to evaluate published literature on MT for stroke performed with TRA in comparison with TFA. 


\section{METHODS}

This study consisted of a retrospective case series and a systematic review of the literature. Institutional review board approval was received. Written procedural consent was obtained from patients or a healthcare proxy.

\section{Case series}

Consecutive patients who underwent MT for large vessel occlusion over a 14-month period between January 1, 2019 and February 29, 2020 were included in the study. Two distinct practices exist among the dual-trained neurointerventionists at our institute. Proponents of the radial-first approach performed TRA. In all other patients, a femoral-first approach was undertaken. Thus, the selection of patients for TRA versus TFA was based on physician preference, rather than on predetermined selection criteria. Although TFA proponents sometimes perform TRA, especially for posterior circulation stroke, no such overlap occurred during the study period. TRA proponents had performed several hundred diagnostic and interventional procedures.

Data were collected on demographics, clinical presentation, occlusion site, comorbidities, body mass index (BMI), Alberta Stroke Program Early CT Score (ASPECTS), administration of intravenous (IV) tissue plasminogen activator (tPA), devices used, and MT techniques (stent retriever alone, a direct aspiration first pass technique (ADAPT), or Solumbra). Primary outcomes included rate of successful reperfusion (thrombolysis in cerebral infarction (TICI) $>2$ b), number of passes, access-site complications, and 3-month mortality and favorable functional outcomes (modified Rankin Scale (mRS) score 0-2).

\section{Systematic literature review \\ Search criteria}

The systematic literature review was conducted and reported according to the Preferred Reporting Items for Systematic Reviews and Meta-Analyses (PRISMA) guidelines. We searched Google Scholar, Public/Publisher Medline (PubMed), the Cochrane Library, the Excerpta Medica database (EMBASE), and the Cumulative Index to Nursing and Allied Health Literature (CINAHL). Searches included the following combinations of words and phrases: "transradial" or "radial," "stroke" or "cerebrovascular accident" or "CVA," and "mechanical thrombectomy". A total of 1575 published studies, abstracts, book chapters, and case reports were identified. Studies that had no English translation were excluded. All studies that had more than 10 patients treated with MT for stroke through TRA were included.

\section{Qualitative analysis}

The 10 included studies were assessed with the 'Quality Appraisal Checklist for Case Studies' tool developed by the Institute of Health Economics. ${ }^{16}$ Seven "Yes/No" questions about the study objective, study design, and study population were answered (online supplemental table 1). "Were the hypothesis, aim, and objective of the study clearly stated?" received a "Yes" if a clearly stated objective was present. "Were the characteristics of the patients included in the study described?" received a "Yes" if a measure of reperfusion success, the location of occlusion, accesssite complications, and functional outcome were reported.

\section{Data extraction}

Patient demographics, operative details, complications, and angiographic and functional outcomes were extracted from the selected studies. Patient demographics included patient age, sex, and occlusion laterality and location. Operative details included the means of recanalization (stent retriever, ADAPT, or Solumbra technique), BGC use, and information related to first-pass recanalization or failure to reach the target occlusion. Angiographic outcome included TICI score, with a score of $2 \mathrm{~b}$ or 3 considered successful revascularization. Complications noted included both access-site complications and incidents of intracranialhemorrhage (ICH). Functional outcome measures included mRS score (with a score of $0-2$ indicating good outcome) and mortality at 3 months.

\section{Statistical analyses}

\section{Case series}

A descriptive analysis was performed. Continuous data with a normal distribution were presented as means and SD. Data with a skewed distribution were presented as medians and ranges. We compared TRA versus TFA groups using independent Student's t-test and Chi square test for continuous and categorical variables, respectively.

\section{Meta-analysis}

The TRA patient cohorts in all included studies $(n=9)$ were combined, and the Freeman-Tukey transformation was used to calculate the weighted summary proportion of successful reperfusion under the random effects model in MedCalc (www. medcalc.org). Studies that compared TFA to TRA $(n=2)$ were combined with our data. The odds ratio (OR) of successful reperfusion and first-pass recanalization was calculated from the comparison studies. TRA was treated as the intervention and TFA was treated as the control. The OR was calculated using the heterogeneity statistic under the random effects model in MedCalc. Forest plots were generated with pooled effects and inconsistency $\left(I^{2}\right)$ was calculated.

\section{RESULTS}

\section{Case series}

Two-hundred and twenty-two patients were included in our series. Mean age was $69.9 \pm 15.5$ years; 120 (54.1\%) were women. One hundred and twenty-nine patients $(58.1 \%)$ underwent MT with TFA and 93 (41.9\%) underwent MT with TRA. A comparison of clinical characteristics and outcome data is provided in table 1 .

The rate of successful recanalization (TICI $\geq 2 \mathrm{~b}$ ) was $79.6 \%$ for TRA compared with $91.4 \%$ for TFA $(\mathrm{P}=0.01)$. The mean number of passes for the TRA cohort was higher than that for the TFA cohort $(2.4 \pm 1.6$ vs $1.8 \pm 1.2, \mathrm{P}=0.014)$. The rate of first-pass effect was higher for TFA than TRA (50.4\% vs 45.2\%), without statistical significance $(\mathrm{P}=0.28)$. The rate of access-site complications was higher in the TFA cohort (3.9\% vs $0.8 \%$ ), again without statistical significance $(\mathrm{P}=0.20)$. Three-month mortality for the TFA cohort was $22.1 \%$ versus $40.9 \%$ for the TRA cohort $(\mathrm{P}=0.004)$. The rate of 3 -month favorable functional outcomes was higher in the TFA group $(51.3 \%$ vs $34.1 \%$, $\mathrm{P}=0.015$; table 1$)$. There was no difference in mortality or favorable outcomes between anterior and posterior circulation for either of the groups (table 1).

\section{Systematic review}

Ten studiesinvolving 351 patients treated with TRA were included in the systematic review. ${ }^{14} 910$ 13-15 17-19 The selection of studies is shown as a PRISMA flow diagram (online supplemental figure 1). Distribution by sex was reported by 
Table 1 Clinical characteristics and procedural outcomes of the case series

\begin{tabular}{|c|c|c|c|}
\hline Variable & $\begin{array}{l}\text { TFA } \\
129 \text { patients } \\
\text { Mean } \pm \text { SD or } \\
n(\%)\end{array}$ & $\begin{array}{l}\text { TRA } \\
93 \text { patients } \\
\text { Mean } \pm \text { SD or } \\
n(\%)\end{array}$ & $P$ value \\
\hline Age (years) & $69.1 \pm 15.8$ & $71.0 \pm 15.1$ & 0.36 \\
\hline Male $(\mathrm{n}(\%))$ & $60(46.5)$ & $40(43.0)$ & 0.84 \\
\hline NIHSS score at presentation & $14.9 \pm 7.4$ & $13.8 \pm 8.0$ & 0.34 \\
\hline Baseline mRS score & $0.88+1.2$ & $0.84+1.3$ & 0.84 \\
\hline ASPECTS & $8.6+1.7$ & $8.8+1.8$ & 0.15 \\
\hline BMI & $28.4+7.3$ & $27.8+8.6$ & 0.26 \\
\hline Diabetes mellitus & $39(30.2)$ & $25(26.9)$ & 0.9 \\
\hline Hypertension & $83(64.3)$ & $69(74.2)$ & 0.12 \\
\hline Congestive heart failure & $17(13.2)$ & $9(9.7)$ & 0.4 \\
\hline COPD & $13(10.1)$ & $7(7.5)$ & 0.5 \\
\hline IV tPA administered & $38(29.5)$ & $25(26.9)$ & 0.68 \\
\hline Door-to-recanalization time (min) & $66.1 \pm 35.5$ & $60.4 \pm 29.1$ & 0.25 \\
\hline Door-to-access time (min) & $44.74 \pm 35.1$ & $34.0 \pm 11.04$ & 0.21 \\
\hline Left-sided target lesion & $57(44.2)$ & $42(45.2)$ & 0.76 \\
\hline M1 & $48(37.2)$ & $42(45.2)$ & 0.07 \\
\hline M2 & $33(25.6)$ & $24(25.8)$ & \\
\hline ICA & $30(23.2)$ & $13(14.0)$ & \\
\hline Posterior circulation & $9(7.0)$ & $11(11.8)$ & \\
\hline Other locations* & $9(7.0)$ & $3(32.2)$ & \\
\hline Stent only & 16 & 37 & $<0.001$ \\
\hline ADAPT & 21 & 5 & \\
\hline Solumbra & 92 & 43 & \\
\hline \multicolumn{4}{|l|}{ Sheath size } \\
\hline $9 F$ & $54(41.9)$ & 0 & \\
\hline $8 \mathrm{~F}$ & $64(49.6)$ & 0 & \\
\hline $6 \mathrm{~F}$ & $11(8.5)$ & $93(100)$ & \\
\hline Successful recanalization $(\mathrm{TICl} \geq 2 \mathrm{~b}$ ) & $118(91.4)$ & $74(79.6)$ & 0.01 \\
\hline Number of passes & $\begin{array}{l}1.8 \pm 1.2 \\
(\text { median=1) }\end{array}$ & $\begin{array}{l}2.4 \pm 1.6 \\
(\text { median=2) }\end{array}$ & 0.014 \\
\hline First-pass effect & $65(50.4)$ & $42(45.2)$ & 0.28 \\
\hline sICH & $7(5.4)$ & $4(4.3)$ & 0.7 \\
\hline Access-site complications & $5(3.9)$ & $1(0.8)$ & 0.20 \\
\hline Patients with 3 months of follow-up & 113 & 88 & \\
\hline 3- month mortality & $25(22.1)$ & $36(40.9)$ & 0.004 \\
\hline 3-month favorable outcomest & $58(51.3)$ & $30(34.1)$ & 0.015 \\
\hline \multicolumn{4}{|l|}{ Posterior circulation only } \\
\hline 3-month mortality & $3(33.3)$ & $4(36.3)$ & 0.67 \\
\hline 3-month favorable outcomest & $5(55.5)$ & $5(45.4)$ & 0.94 \\
\hline
\end{tabular}

*Other locations include tandem occlusion, occlusion of M3 segment, or anterior cerebral artery occlusion.

tmRS score $0-2$.

.tPA; tissue plasminogen activator; $A C A$, anterior cerebral artery; ADAPT, a direct aspiration first pass technique; ASPECTS, Alberta Stroke Program Early CT Score; $B G C$, balloon-guide catheter or catheters; BMI, body mass index; COPD, chronic obstructive pulmonary disease; $F$, French; ICA, internal carotid artery; IV, intravenous; $M 1$, first segment of middle cerebral artery; $M 2$, second segment of middle cerebral artery; M3, third segment of middle cerebral artery; mRS, modified Rankin Scale; NIHSS, National Institutes of Health Stroke Scale; SD, standard deviation; sICH, symptomatic intracranial hemorrhage; TFA, transfemoral access; TICl, thrombolysis in cerebral infarction; tPA, tissue plasminogen activator; TRA, transradial access. eight studies. ${ }^{4910141517-19}$ In those studies, women constituted $51.2 \%$ of all patients. Most patients were treated for an anterior circulation occlusion (88.9\%). Only five studies provided a breakdown of various thrombectomy techniques. ${ }^{4} 9101417$ In those five studies, stent retrievers first, ADAPT, and Solumbra techniques were used with a frequency of $35.2 \%, 33.8 \%$, and $31.7 \%$, respectively. Of six studies 4910131718 with available data, only two studies described the use of BGCs for a proportion of patients $(12.4 \%) .^{9}{ }^{13}$ Five studies reported on failure to reach the target, which was encountered in 9.3\% cases. ${ }^{1491017}$ This data point was not reported in other studies. Only four studies reported on the rate of $\mathrm{ICH}$, which was on average $4.2 \%$ in those studies. ${ }^{43-15}$

Only two studies reported mRS scores and mortality beyond 3 months. ${ }^{4}{ }^{17}$ In those studies, $39.4 \%$ of the patients achieved a favorable functional outcome (mRS 0-2) after 3 months and $30.3 \%$ died. Among the 10 studies, ${ }^{1} 491013-1517-19$ 84.0\% of all patients treated with TRA achieved successful revascularization (TICI $\geq 2 b$ ). A forest plot of the proportion of successful revascularization among all patients can be found in figure 1 . The rate of successful reperfusion varied from $57.1 \%$ to $95.6 \%$. The heterogeneity in the results of successful revascularization was significant $(67.5 \% ; \mathrm{P}=0.001)$.

\section{Transradial versus transfemoral analysis}

There were a total of 772 patients in the four studies comparing transradial MT to transfemoral MT, including the present case series. ${ }^{13-1518}$ A total of 303 patients had TRA and 469 had TFA (table 2). Most patients were treated for an anterior large vessel occlusion $(90.4 \%$ of the transradial group, $95.1 \%$ of the transfemoral group). In addition to our case series, only Khanna et $a l^{14}$ presented the frequency of each thrombectomy technique. Only two studies reported on the use of BGCs. ${ }^{13} 18$ BGCs were used more frequently in the transfemoral group (58.4\%) than the transradial group (5\%). There were two $(0.67 \%)$ reported access-site complications among the transradial group, whereas there were $27(5.8 \%)$ in the transfemoral group. The frequency of symptomatic ICH reported in three studies ${ }^{13-15}$ and our case series was $4.78 \%$ in the transradial group and $8.06 \%$ in the transfemoral group. Successful reperfusion was achieved in $88.8 \%$ of the transradial group and $93.2 \%$ of the transfemoral

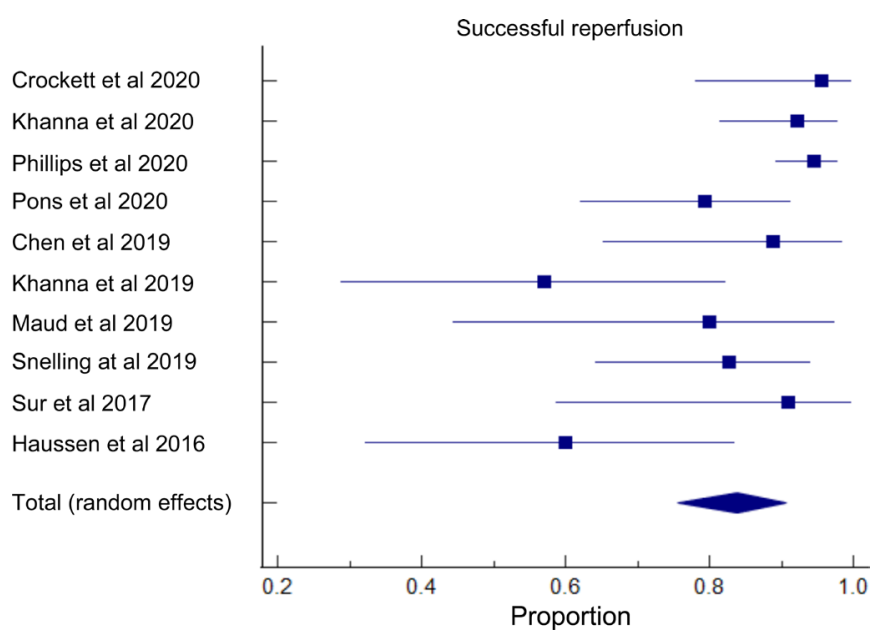

Figure 1 Forest plot showing proportion of successful reperfusion in various transradial access (TRA) studies. Notice the variation from $57.1 \%$ to $95.6 \%$. $1^{2}=67.55 \%$, heterogeneity $P=0.0011$, no random effects $P$ value. 
A

B
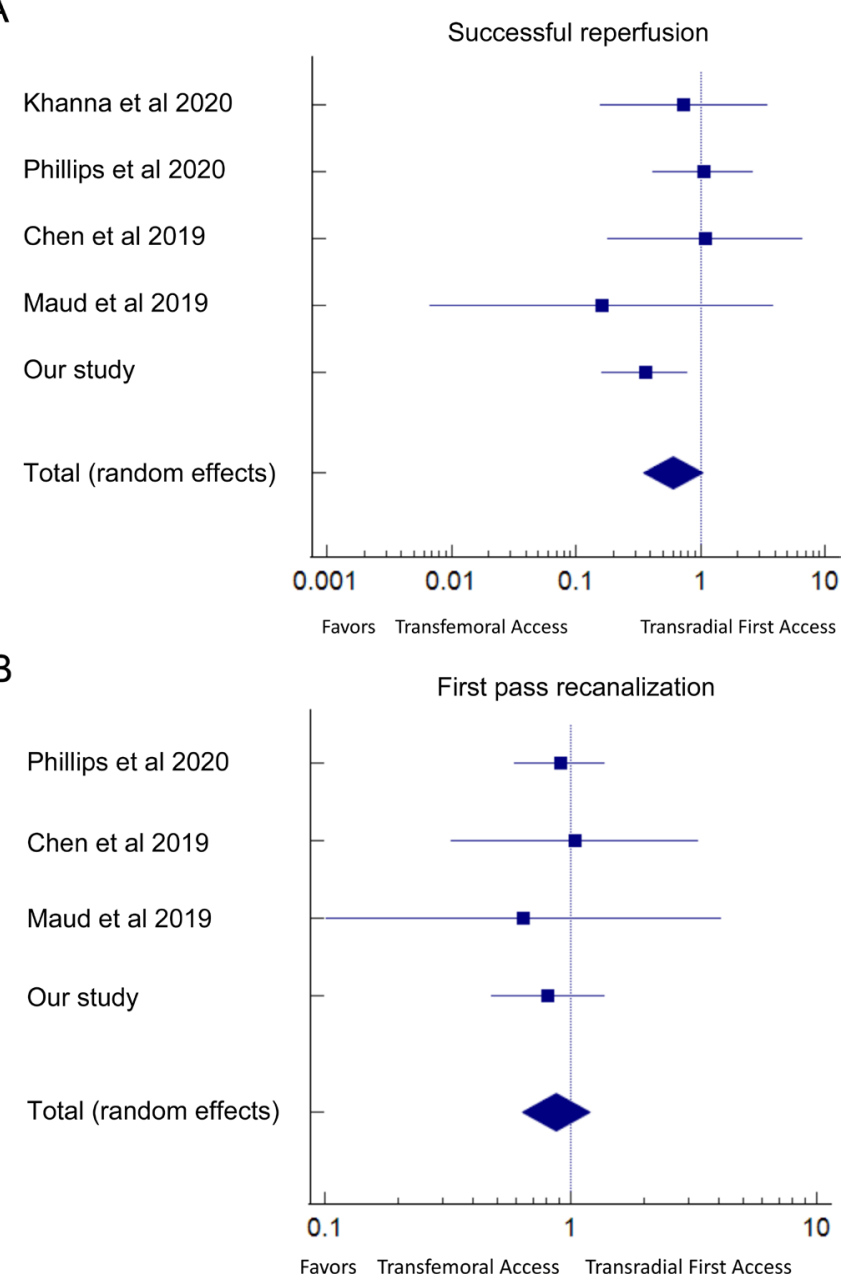

Figure 2 (A) Forest plot for the odds ratio (OR) of successful reperfusion of transradial access (TRA) to transfemoral access (TFA) cohorts. The overall results favor TFA. $I^{2}=3.34 \%$, heterogeneity $P=0.3876$, random effects $P=0.073$. (B) Forest plot for the OR of firstpass recanalization of TRA to TFA. The overall effects favor the use of TFA. $I^{2}=0.00 \%$, heterogeneity $P=0.96$, random effects $P=0.40$.

group. However, the trend favoring TFA was not significant $(\mathrm{P}=0.073)$. A forest plot for the OR of successful reperfusion of the transradial to transfemoral groups is provided in figure $2 \mathrm{~A}$. Heterogeneity was $3.34 \%(\mathrm{P}=0.38)$. First-pass recanalization was achieved in $50.6 \%$ of the transradial group and $54.2 \%$ of the transfemoral group $(\mathrm{P}=0.96)$. A forest plot for the $\mathrm{OR}$ of first-pass recanalization of transradial to transfemoral groups of patients is provided in figure $2 \mathrm{~B}$. Heterogeneity was $0.0 \%$ $(\mathrm{P}=0.9)$.

Phillips et al reported 3-month mRS scores of 0-2 for only those TRA and TFA groups of patients who had premorbid mRS scores of $0-2 .{ }^{15}$ Therefore, functional outcomes were not reported for eight patients in the TRA group and 31 patients in the TFA group. Due to the lack of complete data, a pooled analysis was not possible. Thus, none of the four studies ${ }^{13-15} 18$ reported complete 3 -month mortality and functional outcomes.

\section{DISCUSSION}

The feasibility of TRA for neurointerventions was first reported in the early 2000s. ${ }^{720}$ However, only recently has this approach been presented as first-line access for a variety of neurointerventions, including diagnostic angiograms, flow diversion,

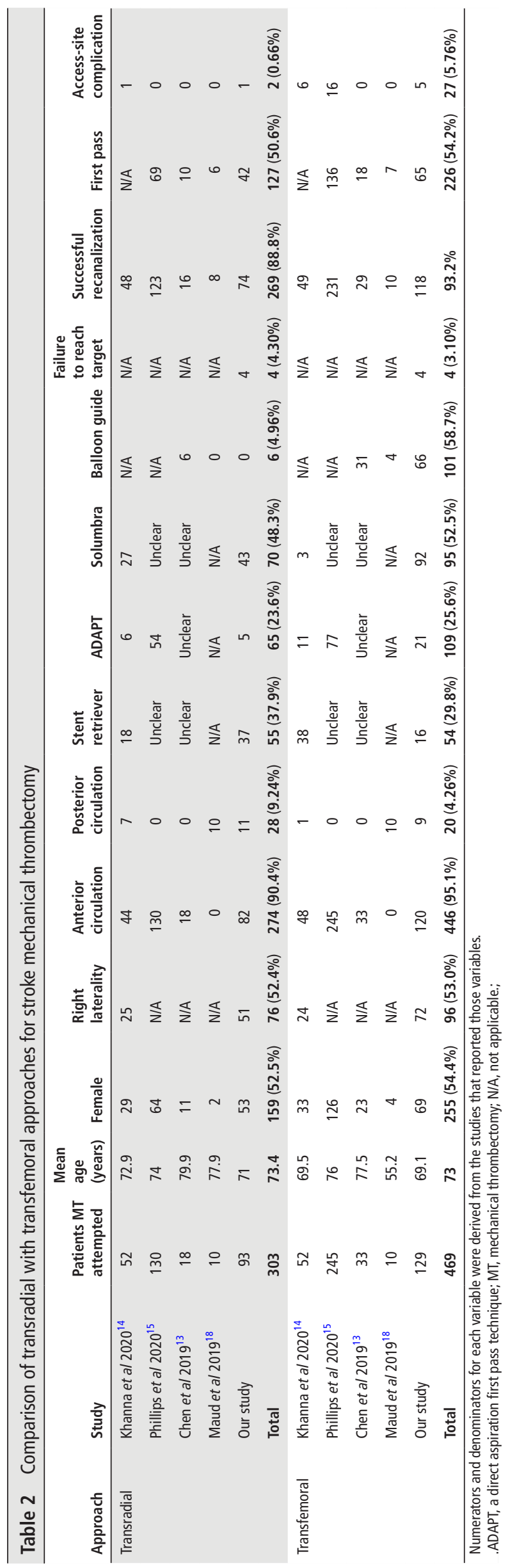


carotid artery stenting, MT, aneurysm coiling, and arteriovenous malformation embolization procedures. ${ }^{1489} 911-132122$ However, it is important to recognize that each of these indications and procedures has different technical demands.

The key to MT is the achievement of rapid successful reperfusion with a minimum number of passes. ${ }^{23} 24$ Several studies have demonstrated the number of passes as the independent predictor of favorable outcomes. ${ }^{23-25}$ Successful reperfusion with a minimum number of passes is achieved through the use of an armamentarium of options, that is, aspiration, stent retriever, or combined use of these techniques with or without flow arrest with a BGC. The definitive evidence to support the use of MT for large vessel occlusion came from clinical trials that mainly used TFA. ${ }^{26}$ As a result, existing guide catheters and aspiration catheters are designed and optimized for femoral access. The technical limitations of radial stroke intervention become strikingly evident when it comes to the use of aspiration catheter and BGCs. Although it can be argued that key clinical trials mainly used various stent retrievers, subsequent trials and studies have shown the effectiveness of the Solumbra technique, aspiration alone, and BGCs for the treatment of stroke. ${ }^{27}$ The use of a BGC and most new large-bore aspiration catheters requires an 8-French (F) system, which is rarely feasible with a transradial approach. In fact, our typical TRA stroke setup consists of a $6 \mathrm{~F}$ sheath-compatible system with a 5F Sofia intermediate catheter (MicroVention) as an aspiration catheter in addition to a stent retriever. ${ }^{8}$ In the studies that compare TRA with TFA, only Chen et al (2019) described the use of a BGC in the TRA group. ${ }^{23}$ Larger aspiration catheters provide greater surface area for aspiration interaction at the face of the clot with or without a stent retriever, resulting in increased efficiency of clot removal. ${ }^{29} 30$

In our own series of TRA stroke interventions, techniques have evolved significantly and continue to do so. Even in this cohort analysis of recent patients, the proportion of stent-only interventions in the TRA cohort (table 1) no longer reflects the state of practice. As with any technique, continuing to address shortcomings, trialing newer devices or technical approaches, over time will lead to better outcomes.

The current series and systematic review are important for various reasons. First, we highlight that a paucity of data are available on the comparative effectiveness of transradial and transfemoral approaches. There is marked variation in the rates of successful reperfusion with TRA among various studies, ranging from $57.1 \%$ to $95.6 \%$ (table 2). The large variation in the rates of successful reperfusion can be multifactorial and may include factors like operator experience, technique, and site of large vessel occlusion. The impact of various variables on the success of reperfusion through TRA needs more studies. Additionally, it is not prudent to look at the TRA for stroke data in isolation. A radial-first approach cannot be advocated without sufficient evidence of the superiority or non-inferiority of TRA in comparison with TFA, which is limited at this point. For example, in addition to our case series, there were only three other retrospective studies that compared TRA with TFA. Thus, our meta-analysis included only 303 patients in the TRA group and 469 in the TFA group. None of the studies other than our case series reported 3-month mortality and functional outcomes for the complete dataset of included patients. These are outcome parameters that we believe are critical to any comparison because survival and functional independence of patients come first.

Moreover, we show that TFA is associated with higher recanalization rates along with lower mortality and improved functional outcomes. The improved mortality and functional outcomes may be a direct result of higher rates of successful reperfusion with larger aspiration catheters and better flow control with the use of BGCs.

The often-cited advantages associated with TRA of fewer access-site complications, increased patient comfort, and reduced length of stay are less pertinent to stroke patients who often present with poor neurological examination findings. These advantages are of least concern to these patients. In fact, despite a higher although non-significant percentage of accesssite complications, none of the patients with TFA required a major intervention for resolution. Based on the findings of the present study, the effect of the majority of such complications on did not influence 3-month outcomes.

The present systematic review also highlights the heterogeneity of outcomes with TRA. For example, as mentioned, the pooled rate of successful reperfusion varies from $57.1 \%$ to $95.6 \%$. This may be due to varying experience of the operators. However, this wide variation in successful recanalization rates raises questions as to whether the universal adoption of 'radial first' for stroke is worth the compromise of patient care. Is the operator learning curve and compromised patient care worthy of the title of 'radial first'?

\section{Limitations}

There are some limitations of our case series. The radiological outcomes were not adjudicated by a core laboratory; however, the number of passes, which was also significantly lower for TFA, is not an outcome that adjudication could affect. The choice of devices and techniques in the TFA and TRA cohorts was variable. Although all operators in each group had several years of experience before the current study period, operator skill and experience could have influenced the outcomes of each cohort in this study. The specific limitations of the systematic review included a high degree of data heterogeneity. These limitations can be addressed with prospective, core laboratoryadjudicated studies; however, for now, the present study calls for more evidence before a radial-first approach can be adopted more widely.

\section{CONCLUSIONS}

The current case series demonstrates a higher successful reperfusion rate, fewer passes, lower 3-month mortality, and improved 3 -month functional outcomes with TFA. The systematic review showed statistically non-significant trends in favor of femoral access with regards to recanalization rate. A pooled analysis was not possible for number of passes, 3-month mortality, and favorable outcomes.
Author affiliations
${ }^{1}$ Department of Neurosurgery, Jacobs School of Medicine and Biomedical Sciences, University at Buffalo, Buffalo, New York, USA
${ }^{2}$ Department of Radiology, Jacobs School of Medicine and Biomedical Sciences, University at Buffalo, Buffalo, New York, USA
${ }^{3}$ Department of Neurosurgery, Gates Vascular Institute at Kaleida Health, Buffalo, New York, USA
${ }^{4}$ Canon Stroke and Vascular Research Center, University at Buffalo, Buffalo, New York, USA
${ }^{5}$ Jacobs Institute, Buffalo, New York, USA
${ }^{6}$ Jacobs School of Medicine and Biomedical Sciences, University at Buffalo, Buffalo, New York, USA
${ }^{7}$ Department of Neurology, Jacobs School of Medicine and Biomedical Sciences, University at Buffalo, Buffalo, New York, USA
${ }^{8}$ Department of Bioinformatics, Jacobs School of Medicine and Biomedical Sciences, University at Buffalo, Buffalo, New York, USA

Acknowledgements The authors thank Paul H Dressel BFA for formatting the illustrations and Debra J Zimmer for editorial assistance. 
Contributors Conception and design: AHS, MW, EIL. Acquisition of the data: all authors. Analysis and interpretation of the data: all authors. Drafting the manuscript: MW. Critically revising the manuscript: all authors. Reviewing submitted version of manuscript: all authors.

Funding The authors have not declared a specific grant for this research from any funding agency in the public, commercial or not-for-profit sectors.

Competing interests AHS: Financial interest/investor/stock options/ownership: Adona Medical, Inc., Amnis Therapeutics (purchased by Boston Scientific October 2017), Blink TBI Inc., Buffalo Technology Partners Inc., Cerebrotech Medical Systems, Inc., Cognition Medical, Endostream Medical Ltd., Imperative Care, International Medical Distribution Partners, Neurovascular Diagnostics Inc., Q'Apel Medical Inc., Rebound Therapeutics Corp. (purchased 2019 by Integra Lifesciences, Corp.), Rist Neurovascular Inc., Sense Diagnostics, Inc., Serenity Medical Inc., Silk Road Medical, Spinnaker Medical, Inc., StimMed, Synchron, Three Rivers Medical Inc., Vastrax, LLC, VICIS, Inc., Viseon Inc.; Consultant/advisory board: Amnis Therapeutics, Boston Scientific, Canon Medical Systems USA Inc., Cerebrotech Medical Systems Inc., Cerenovus, Corindus Inc., Endostream Medical Ltd., Imperative Care, Inc., Integra LifeSciences Corp., Medtronic, MicroVention, Minnetronix Neuro, Inc., Northwest University-DSMB Chair for HEAT Trial, Penumbra, Q'Apel Medical Inc., Rapid Medical, Rebound Therapeutics Corp. (purchased by Integra LifeSciences Corp.), Serenity Medical Inc., Silk Road Medical, StimMed, Stryker, Three Rivers Medical, Inc., VasSol, W.L. Gore \& Associates; Principal investigator/steering committee for the following trials: Cerenovus NAPA and ARISE II; Medtronic SWIFT PRIME and SWIFT DIRECT; MicroVention FRED \& CONFIDENCE; MUSC POSITIVE; and Penumbra 3D Separator, COMPASS, INVEST, TIGER. JMD: Research grant: National Center for Advancing Translational Sciences of the National Institutes of Health under award number KL2TR001413 to the University at Buffalo; Consulting: Medtronic; Honoraria: Neurotrauma Science, LLC; Shareholder/ownership interests: Cerebrotech, RIST Neurovascular. KVS: Consulting and teaching: Canon Medical Systems Corporation, Penumbra Inc., Medtronic, and Jacobs Institute; Co-Founder: Neurovascular Diagnostics, Inc. ElL: Shareholder/ownership interests: NeXtGen Biologics, RAPID Medical, Claret Medical, Cognition Medical, Imperative Care (formerly the Stroke Project), Rebound Therapeutics, StimMed, Three Rivers Medical; National principal investigator/steering committees: Medtronic (merged with Covidien Neurovascular) SWIFT Prime and SWIFT Direct Trials; Honoraria: Medtronic (training and lectures); Consultant: Claret Medical, GLG Consulting, Guidepoint Global, Imperative Care, Medtronic, Rebound, StimMed; Advisory board: Stryker (AIS Clinical Advisory Board) NeXtGen Biologics, MEDX, Cognition Medical, Endostream Medical; Site principal investigator: CONFIDENCE study (MicroVention), STRATIS Study—Sub I (Medtronic). MW, JZ, JN, RHD, HHR, AM, JMC, RJVC III, AS: no competing interests disclosed.

Patient consent for publication Not required.

Ethics approval Written consent was obtained from all patients or their healthcare proxy before procedures were performed. This study was approved by the University at Buffalo institutional review board, STUDY 030-403427.

Provenance and peer review Not commissioned; externally peer reviewed.

Data availability statement Data that support the findings of this study are available from the corresponding author on reasonable request.

Supplemental material This content has been supplied by the author(s). It has not been vetted by BMJ Publishing Group Limited (BMJ) and may not have been peer-reviewed. Any opinions or recommendations discussed are solely those of the author(s) and are not endorsed by BMJ. BMJ disclaims all liability and responsibility arising from any reliance placed on the content. Where the content includes any translated material, BMJ does not warrant the accuracy and reliability of the translations (including but not limited to local regulations, clinical guidelines, terminology, drug names and drug dosages), and is not responsible for any error and/or omissions arising from translation and adaptation or otherwise.

\section{ORCID iDs}

Adnan H Siddiqui http://orcid.org/0000-0002-9519-0059

Muhammad Waqas http://orcid.org/0000-0003-4500-7954

Hamid H Rai http://orcid.org/0000-0002-2784-5957

Jason M Davies http://orcid.org/0000-0002-5225-3072

Elad I Levy http://orcid.org/0000-0002-6208-3724

\section{REFERENCES}

1 Khanna O, Sweid A, Mouchtouris N, et al. Radial artery catheterization for neuroendovascular procedures. Stroke 2019;50:2587-90.

2 Snelling BM, Sur S, Shah SS, et al. Transradial cerebral angiography: techniques and outcomes. J Neurointerv Surg 2018;10:874-81.
3 Snelling BM, Sur S, Shah SS, et al. Transradial access: lessons learned from cardiology. J Neurointerv Surg 2018;10:487-92.

4 Crockett MT, Selkirk GD, Chiu AHY, et al. First line transradial access for posterior circulation stroke intervention; initial 12-month experience at a high volume thrombectomy center. J Clin Neurosci 2020;78:194-7.

5 Rajah GB, Waqas M, Dossani RH, et al. Transradial middle meningeal artery embolization for chronic subdural hematoma using Onyx: case series. J Neurointerv Surg 2020;12:1214-8.

6 Khanna O, Mouchtouris N, Sweid A, et al. Transradial approach for acute stroke intervention: technical procedure and clinical outcomes. Stroke Vasc Neurol 2020;5:103-6

7 Levy El, Kim SH, Bendok BR, et al. Transradial stenting of the cervical internal carotid artery: technical case report. Neurosurgery 2003;53:448-52. discussion 51-2..

8 Munich SA, Vakharia K, McPheeters MJ, et al. Transition to transradial access for mechanical thrombectomy - lessons learned and comparison to transfemoral access in a single-center case series. Oper Neurosurg 2020. doi:10.1093/ons/opaa230

9 Snelling BM, Sur S, Shah SS, et al. Transradial approach for complex anterior and posterior circulation interventions: technical nuances and feasibility of using current devices. Oper Neurosurg 2019;17:293-302.

10 Sur S, Snelling B, Khandelwal P, et al. Transradial approach for mechanical thrombectomy in anterior circulation large-vessel occlusion. Neurosurg Focus 2017:42:E13.

11 Waqas M, Vakharia K, Dossani RH, et al. Transradial access for flow diversion of intracranial aneurysms: case series. Interv Neuroradiol 2020;24:159101992093896.

12 Joshi KC, Beer-Furlan A, Crowley RW, et al. Transradial approach for neurointerventions: a systematic review of the literature. J Neurointerv Surg 2020;12:886-92

13 Chen SH, Snelling BM, Sur S, et al. Transradial versus transfemoral access for anterior circulation mechanical thrombectomy: comparison of technical and clinical outcomes. J Neurointerv Surg 2019;11:874-8.

14 Khanna O, Velagapudi L, Das S, et al. A comparison of radial versus femoral artery access for acute stroke interventions. J Neurosurg 2020:1-6.

15 Phillips TJ, Crockett MT, Selkirk GD, et al. Transradial versus transfemoral access for anterior circulation mechanical thrombectomy: analysis of 375 consecutive cases. Stroke Vasc Neurol 2020. doi:10.1136/svn-2020-000624

16 Evers S, Goossens M, de Vet $\mathrm{H}$, et al. Criteria list for assessment of methodological quality of economic evaluations: consensus on health economic criteria. Int I Technol Assess Health Care 2005;21:240-5.

17 Haussen DC, Nogueira RG, DeSousa KG, et al. Transradial access in acute ischemic stroke intervention. J Neurointerv Surg 2016;8:247-50.

18 Maud A, Khatri R, Chaudhry MRA, et al. Transradial access results in faster skin puncture to reperfusion time than transfemoral access in posterior circulation mechanical thrombectomy. J Vasc Interv Neurol 2019;10:53-7.

19 Pons RB, Caamaño IR, Chirife OS, et al. Transradial access for diagnostic angiography and interventional neuroradiology procedures: a four-year single-center experience. Interv Neuroradiol 2020;26:506-13.

20 Levy El, Boulos AS, Fessler RD, et al. Transradial cerebral angiography: an alternative route. Neurosurgery 2002:51:335-42. discussion 40-2.

21 Brunet M-C, Chen SH, Sur S, et al. Distal transradial access in the anatomical snuffbox for diagnostic cerebral angiography. J Neurointerv Surg 2019;11:710-3.

22 Jha N, Selkirk G, Crockett MT, et al. Transradial intracranial aneurysm treatment via an aberrant right subclavian artery. BMJ Case Rep 2020;13:e234078.

23 Baek J-H, Kim BM, Heo JH, et al. Number of stent retriever passes associated with futile recanalization in acute stroke. Stroke 2018;49:2088-95.

24 Kharouba R, Gavriliuc P, Yaghmour NE, et al. Number of stentriever passes and outcome after thrombectomy in stroke. J Neuroradiol 2019;46:327-30.

25 García-Tornel Álvaro, Requena M, Rubiera M, et al. When to stop. Stroke 2019;50:1781-8

26 Goyal M, Menon BK, van Zwam WH, et al. Endovascular thrombectomy after large-vessel ischaemic stroke: a meta-analysis of individual patient data from five randomised trials. Lancet 2016;387:1723-31.

27 Turk AS, Siddiqui A, Fifi JT, et al. Aspiration thrombectomy versus stent retriever thrombectomy as first-line approach for large vessel occlusion (COMPASS): a multicentre, randomised, open label, blinded outcome, non-inferiority trial. Lancet 2019;393:998-1008.

28 Zaidat 00 , Mueller-Kronast NH, Hassan AE, et al. Impact of balloon guide catheter use on clinical and angiographic outcomes in the STRATIS stroke thrombectomy registry. Stroke 2019;50:697-704.

29 Alawieh A, Chatterjee AR, Vargas J, et al. Lessons learned over more than 500 stroke thrombectomies using ADAPT with increasing aspiration catheter size. Neurosurgery 2020;86:61-70.

30 Delgado Almandoz JE, Kayan Y, Wallace AN, et al. Larger ACE 68 aspiration catheter increases first-pass efficacy of ADAPT technique. J Neurointerv Surg 2019;11:141-6. 